\title{
Is it impossible to inhibit isoluminant items, or does it simply take longer? Evidence from preview search
}

\author{
JASON J. BRAITHWAITE, JOHAN HULLEMAN, DERRICK G. WATSON, and GLYN W. HUMPHREYS \\ University of Birmingham, Birmingham, England
}

\begin{abstract}
Visual search can be facilitated when participants receive a preview of half the distractors (the preview benefit in search; Watson \& Humphreys, 1997). Donk and Theeuwes (2001) have argued that preview-based benefits are abolished if the display items are isoluminant to a background. This is consistent with the preview benefit being due to onset capture by the new stimuli. In contrast, the present experiments challenge this suggestion and show that preview benefits can occur under isoluminant conditions, providing that they are given enough time to occur. In Experiment 1, we showed that a preview benefit can occur even with isoluminant stimuli, provided that the old items are previewed for a sufficient time. In Experiment 2, we tested and rejected the idea that this advantage is due to low-level sensory fatigue for the preview stimuli. These findings indicate that the preview effect is not caused solely by onset capture.
\end{abstract}

Performance in visual search tasks can be greatly improved if observers are given a preview of half of the irrelevant distractors in advance of the other distractors and the target (Watson \& Humphreys, 1997, 1998, 2000). Under these preview circumstances, search can be as efficient as it is when only the second set of items is presented and is much more efficient than it is with the full combined display of the items appearing together (a full-set search baseline). Originally, Watson and Humphreys (1997) suggested that for static stimuli, this preview benefit was the result of goal-directed inhibition directed toward the old, irrelevant stimuli-a process they termed visual marking (Watson \& Humphreys, 1997, 1998, 2000, 2002). The inhibitory filtering of irrelevant information aided capture mechanisms and increased the signal-to-noise ratio for subsequently appearing important and relevant new information (see Watson, Humphreys, \& Olivers, 2003). Further evidence for old items being inhibited has been provided by cases in which probe detection tasks are combined with visual search. For instance, probe dot detection is worse when the dots fall at the locations of old items, relative to when they fall at the locations of new stimuli (Olivers \& Humphreys, 2002; Watson \& Humphreys, 2000). Crucially, this deficit in probe detection at old locations is found only when participants are engaged in a search task in which new items must be prioritized, and it is not found when probe detection is the primary task. This is consistent with the suggestion that the

This research was supported by a British Academy postdoctoral fellowship awarded to the first author and an MRC grant to the fourth author. Correspondence concerning this article should be addressed to J. J. Braithwaite, Behavioral Brain Sciences Centre, School of Psychology, University of Birmingham, Edgbaston, Birmingham B15 2TT, England (e-mail: j.j.braithwaite@bham.ac.uk). preview benefit is influenced by the current goal state of the observer, which is to prioritize the new and to ignore the old stimuli.

Similar evidence for inhibitory effects in preview search, but linked to the features and not just to the locations of old items, has come from Braithwaite and colleagues (Braithwaite, 2002; Braithwaite \& Humphreys, 2003; Braithwaite, Humphreys, \& Hodsoll, 2003, 2004; Braithwaite, Humphreys, \& Hulleman, 2005; see also Gibson \& Jiang, 2001; Olivers \& Humphreys, 2002). In these studies, target search was slowed if the target carried feature properties of the old items, and detection was slowed for probes that fell on new distractors that shared the same feature. Collectively, these studies suggest that old, irrelevant items can be filtered from search on the basis of inhibition directed to both their locations and their featural properties.

\section{Noninhibitory Accounts for the Preview Benefit}

Alternative accounts of the preview benefit can also be offered. For instance, Donk and Theeuwes (2001) suggested that the preview benefit simply reflects automatic attentional capture by the onsets from the new stimuli. Here, search is improved not because old items are deprioritized, reducing their chances of selection, but because the new items automatically capture attention, improving their chances of selection. This, too, would predict that search will be restricted to just the new items, but without recourse to any notion of inhibitory coding at the old locations. In a further proposal, Jiang, Chun, and Marks (2002) argued that the preview benefit is caused by the temporal segmentation of the old and the new displays, which allows participants to attend to the new group. By this account, the old and the new items are grouped and individuated on the basis of temporal asynchrony signals, and observers simply direct their attention to the new, rel- 
evant target-carrying group. Again, there is no need to assume any active inhibitory processing at the old locations

Donk and Theeuwes (2001) examined preview search with stimuli that were isoluminant with their background. This eliminated any abrupt luminance-defined onset signal that might have accompanied the presentation of the stimuli. There were three conditions: (1) Both the preview and the search displays were isoluminant with their background (i.e., there were no abrupt onset cues in either display); (2) the preview arrived with an abrupt onset, but the search display did not (but note that in this condition, the luminance of the background was ramped during the preview period, so that the preview items were isoluminant with the background when the search set was added); and (3) the preview display was isoluminant, whereas the search display arrived with an abrupt onset. The results showed that the preview benefit was abolished either when the preview and the search displays were isoluminant or when the search display alone was isoluminant with the background. This result has been taken to strongly suggest that it is critical that new items be defined by onsets (Donk \& Theeuwes, 2001) and is consistent with the need for attentional capture by new onsets (see Yantis, 1993, 1996).

\section{Revisiting Preview Benefits at Isoluminance}

In their original study, Donk and Theeuwes (2001) argued that onsets were crucial in mediating the preview benefit. This was based largely on their finding that search performance varied as a function of the number of old items when the search stimuli were isoluminant with the background, but not when the search stimuli appeared as onsets. However, in the second experiment of Donk and Theeuwes, the slope function relating reaction times (RTs) to old elements (OEs) actually tended to be shallower than that relating RTs to new isoluminant elements (NEs; 30.8 vs. $39.2 \mathrm{msec} /$ item; $p=.095$ for target-present trials, based on only 8 participants). The direction of this effect, with old items having a reduced impact as compared with when both were isoluminant on presentation of the search display, is consistent with inhibitory filtering being applied to the old items. In addition, given the expectation that the $\mathrm{OE}$ performance would be shallower than that for the NEs, a one-sided $p$ value might have been more appropriate. In a further combined analysis of the data from Experiments 1 and 2 in their study, they found an $F$ value of 3.53, with an associated (two-sided) $p$ of .08, with the OEs tending to have a reduced impact, relative to the NEs. There is certainly a suspicion here that OEs do not compete as strongly as new distractors, even when both are isoluminant with the background when search commences. Furthermore, since a visual-marking account would actually directly predict that OE performance will have less of an impact than will NE performance, again a one-sided $p$ value would have been more appropriate, and in this case, it would be a value of $p=.04$ (with the direction of the effect benefiting performance for the old elements, relative to the new elements). This means that, in fact, contrary to their claims, Donk and Theeuwes did, indeed, find a weak effect of inhibitory marking in their original experiments. Our critical reassessment of their own data here suggests that there was indeed evidence for inhibitory filtering at the old locations.

Further evidence for a preview benefit with isoluminant displays has recently been reported by Braithwaite, Humphreys, Watson, and Hulleman (2005). Unlike in Donk and Theeuwes's (2001) study, Braithwaite, Humphreys, et al. (2005) included a full-set baseline condition in which all the items used in preview search were presented together. When compared with the preview conditions, this baseline provides a better measure of whether a preview benefit is present than does simply testing for the effects of the number of old items on search. This is because effects of the number of old items could occur because preview search is relatively inefficient, but it still may remain more efficient than is search in a matched full-set baseline (see, e.g., Humphreys, Watson, \& Jolicœur, 2002, for evidence from dualtask effects on search). Therefore, assessing search only as a function of old- versus new-item display size may well underestimate the presence of a preview benefit (and hence, inhibitory filtering). What, in fact, such a method reveals is that in some situations, marking might not be optimal; it does not necessarily mean that marking is not present to some degree. In support of this, when performance was compared with that for a matched full-set baseline, Braithwaite, Humphreys, et al. (2005) found that there was a preview benefit even when the new items were isoluminant with their background, when the preview stimuli were nonisoluminant. This strongly implies that new onsets alone are not a necessary condition for a preview advantage.

There are further problems with the onset capture proposal. For example, the onset capture view fails to explain why probe detection suffers at old, as compared with neutral, locations, since attention should be drawn away from both locations toward the new search stimuli (Humphreys, Stalmann, \& Olivers, 2004). It also fails to account for the disruption to search when targets carry the feature values of old stimuli (even when the target is a salient singleton in the new display; see Braithwaite et al., 2004; Olivers \& Humphreys, 2003). Humphreys et al. (2004) also presented search stimuli by changing the color of contours in a background grid, and luminance noise was also added to individual pixels to minimize the chances that search stimuli were defined by onsets. Despite this, there was a clear benefit in the preview condition, as compared with a baseline in which both the old and the new stimuli appeared together.

One difference between the stimuli used by Donk and Theeuwes (2001) and those employed by Braithwaite, Humphreys, et al. (2005) and Humphreys et al. (2004) is that in Donk and Theeuwes, all the stimuli were isoluminant with the background once search was initiated. In Humphreys et al., the search stimuli were isoluminant with the grid, but the grid itself (and hence, the search shapes) was not isoluminant with the background. Braithwaite, Humphreys, et al. also employed nonisoluminant old distractors in some conditions. This difference may be important. In particular, it may be difficult to code 
the locations of stimuli that are isoluminant with their background (see Livingstone \& Hubel, 1987), yet efficient location coding may be important for ignoring the old items and establishing a preview benefit. Watson and Humphreys (1997) originally argued that the benefit was contingent on inhibition of the locations of old stimuli; as a consequence, inhibition may be difficult to apply when location coding is inefficient. However, even if location information is difficult to encode, encoding may still be possible if participants are allowed sufficient time. According to the marking account, a preview benefit may then emerge because old locations, once coded, may be suppressed (Watson \& Humphreys, 1997, 1998). This idea was tested here, where we examined preview search with stimuli that were isoluminant with their background but used relatively long, as well as "standard," preview durations. In their initial study, Watson and Humphreys (1997) reported that the preview benefit had a relatively long time course, with an optimal benefit emerging only when the preview was presented for $400 \mathrm{msec}$ or longer. In Donk and Theeuwes, the preview duration was fixed at around $1,000 \mathrm{msec}$, but this may not be long enough to encode the locations of isoluminant stimuli, to support their subsequent inhibition. In terms of understanding the mechanisms of search, it is crucial to establish whether isoluminant distractors can be filtered if there is sufficient time (indicating that such representations do take longer to encode but, once established, can be ignored) or whether registration within a dynamic detection system is both necessary and sufficient for such information to be inhibited.

In Experiment 1 here, we examined search with stimuli that were isoluminant with their background (as in Donk $\&$ Theeuwes, 2001), using preview durations of 1,000 and $3,000 \mathrm{msec}$. A preview duration of $1,000 \mathrm{msec}$ is usually sufficient time to generate a maximal preview advantage when the stimuli are nonisoluminant (Watson \& Humphreys, 1997). We asked whether a preview advantage can be established with isoluminant stimuli when an extended preview period is given. Note that if a preview benefit were to be found, the effect could not be attributed to attentional capture by new onsets. Consistent with this, we report that a preview benefit does occur with an extended preview duration $(3,000 \mathrm{msec})$.

Experiment 2 was conducted to rule out an alternative low-level sensory explanation of performance. For instance, one reason for the preview benefit could be that with a prolonged preview, there is fatigue of the neurons responding to these items. Due to this neural fatigue, old stimuli may not compete strongly for selection with the new stimuli, even if the new items are not defined by onsets. This, too, would create an advantage for the new stimuli, without recourse to any need for inhibitory coding. To address this, we examined the impact of an attentionally demanding task presented centrally during the extended $(3,000 \mathrm{msec})$ preview duration. This task consisted of a stream of numbers presented sequentially at fixation (every $250 \mathrm{msec}$ ), with observers having to monitor the stream to detect the frequency with which a target number occurred. Under the dual-task condition, the old items remained in the visual field for the same length of time as before, and so any sensory-based neural fatigue should still take place. Indeed, any neural fatigue should be enhanced by the secondary task, since, in this condition, the participants would need to remain fixated at the center of the display in order to discriminate target numbers. This might not be the case in the simple task (preview-only) condition. Neural fatigue effects are maximized when fixation is held through the adaptation period (Theeuwes \& Lucassen, 1993). On the other hand, the secondary task should limit attention to the previews, disrupting both their encoding and their subsequent inhibition (see Humphreys et al., 2002). Under this circumstance, the preview benefit should be reduced.

The secondary task study is also relevant to one other account of the preview benefit in search, which holds that it reflects temporal segmentation of the old and the new displays (Jiang et al., 2002). Essentially, provided that the interval between the preview and the search displays is sufficient, participants should be able to select the new displays without interference from old items. When the old and new items are isoluminant with their background, temporal segmentation may be slowed, since there are no transient onsets present to facilitate the segmentation process. When the interval between the old and the new items is lengthened, then, segmentation may eventually take place. However, since the determining factor there is the time interval between the stimuli, performance should be impervious to a secondary task. Here, the secondary task should not impact on search performance.

Note that this secondary fixation task differs slightly from those used in previous studies of the preview benefit (e.g., Humphreys et al., 2002; Watson \& Humphreys, 1997). In prior studies, simple shadowing tasks were used in which participants might have to decide whether or not a target was present or absent during a trial. However, with the present extended previews, it was possible to detect a target early in the stream and then switch to encoding the old items. This could reduce the effects of the secondary task. To overcome this, we used a secondary task in which the participants had to code the frequency of a target, to ensure attention to the secondary task throughout this period.

\section{EXPERIMENT 1 Effects of Preview Duration}

\section{Method}

\section{Participants}

Twenty-three participants ( 16 of them female, 4 left-handed) took part for course credit or a small payment. The age of the participants ranged from 18 to 34 years, with a mean age of 23.4 years. All were either undergraduate or postgraduate students at the University of Birmingham. All had self-reported normal (including normal color vision) or corrected-to-normal vision.

\section{Stimuli and Apparatus}

All the stimuli and the conditions were generated by a series of computer programs written in Turbo Pascal. The programs were run on a Pentium PC fitted with a 15 -in. Super VGA monitor. These programs recorded all relevant keypress responses and RTs. The distractor stimuli consisted of multiple colored (green) uppercase letter $I \mathrm{~s}$ 
at two different orientations $\left(45^{\circ}\right.$ right $/ 45^{\circ}$ left of vertical). This placed both the central line and the two (upper/lower) lines of this letter shape at diagonal orientations. The line junctions where the central line intercepted the end lines were also slightly overrun (by one screen pixel) to break up the letter shape. The letters had a width of approximately $6 \mathrm{~mm}$ and a length of $7 \mathrm{~mm}$. The target letter was either an uppercase $T$ or an $L$ at four possible orientations $\left(45^{\circ}, 135^{\circ}, 225^{\circ}\right.$, and $\left.315^{\circ}\right)$. Thus, the displays contained only stimuli consisting of diagonal components. These stimuli were displayed on a blue screen background and were viewed at a general distance of approximately $60 \mathrm{~cm}$. The isoluminant properties of the items were set for each participant on the basis of performance from a flicker-fusion color calibration test carried out before the experiment. This calibration test consisted of two square-shaped outlines presented at different eccentricities around a central fixation-cross (these eccentricities approximated the parameters used for the visual search display). The lines of the squares oscillated between the color values (blue and green), to give the sensation of a constant flicker. The participants were asked to concentrate on the central fixation point and to reduce the perceived flicker in the two surrounding outlined shapes, using buttonpress responses that altered the luminance values, until the perceived flicker was minimized. This was taken as the point of isoluminance. Each participant was given practice at the flicker test before completing five experimental calibration trials. The final values were based on average settings from the five trials. These values were then entered into the programs for the displays for that participant.

The items were randomly assigned to an invisible, 48-cell circular matrix. This virtual matrix consisted of three concentric circular grids. The distance from central fixation to the middle of the cells of the first ring measured approximately $19 \mathrm{~mm}$ (containing 8 cells); the second ring, $38 \mathrm{~mm}$ (containing 16 cells); and the third, $58 \mathrm{~mm}$ (containing 24 cells). Search displays were generated by randomly positioning each letter in the middle of individual matrix cells. The preview conditions involved the presentation of half (i.e., 8 or 16) of the distractor letters first (in the first preview display) followed by the remaining half (i.e., 8 or 16) in the second, search display. In a full-set baseline condition, we presented both the combined preview and the search display together. The target, which was present on every trial, was either a rotated $T$ or an $L$ (selected at random, with each orientation occurring equally often). The participants had to respond by pressing the $T$ or $L$ keys to identify the target (irrespective of its orientation).

\section{Design and Procedure}

A $3 \times 2$ (condition $\times$ display size) within-subjects design was used. The three experimental conditions consisted of one simultaneously presented full-set baseline condition and two preview conditions. For the full-set baseline, there was a single presentation of either 8 or 16 items (full). Matched to this full-set condition were two different isoluminant preview conditions that differed in terms of how long the previews were displayed before the search set was presented. In one condition, the isoluminant preview items were presented for a standard duration of $1,000 \mathrm{msec}$ before the isoluminant search set was added (I+I: 1,000). In the other preview condition, the preview duration was $3,000 \mathrm{msec}(\mathrm{I}+\mathrm{I}: 3,000)$. In both the fullset and the preview conditions, all the items were presented without an abrupt onset at isoluminance. The luminance values of the items and of the background were held constant during each trial. Trials within blocks were fully randomized, and block order was randomized across participants. A general block of practice trials, for both the preview and the baseline conditions, was completed at the beginning of the experiment. None of these practice trials was included in the analysis.

Search trials took the following form. Each trial began with the presentation of a plain white fixation cross, which remained visible until the end of each trial. For the baseline condition, after $1,000 \mathrm{msec}$ from fixation onset, the search display was presented and remained visible until a response key was pressed or a time-out period of 10,000 msec had elapsed. This procedure was repeated for each trial for the duration of the experimental block. There was a 1,000-msec delay between the presentations of the individual trials in all the conditions. For the preview conditions, the fixation cross was followed by the preview display for $1,000 \mathrm{msec}$ and then by the target display. The distractors in the preview remained in the same positions when the target display appeared. For the preview presentations, the participants were instructed to remain fixated and not to initiate search until the arrival of the second display, which always contained the target. For these preview conditions, RTs were measured from the onset of the second display. The experiment lasted approximately $50 \mathrm{~min}$.

\section{Results}

The RT data were trimmed for outliers (deemed to be \pm 2.0 standard deviations and any response faster than $200 \mathrm{msec}$ ) and incorrect responses for each participant. An overall $3 \times 2$ (condition $\times$ display size) within-subjects ANOVA was carried out on the remaining correct responses. This revealed significant main effects of condition $[F(2,44)=13.92, p<.001]$ and display size $[F(1,22)=$ $219.03, p<.001]$. The condition $\times$ display size interaction was also significant $[F(2,44)=10.05, p<.001]$. Table 1 shows descriptive intercept and slope data for all the conditions in Experiment 1.

\section{Preview Versus Full-Set Baseline Comparisons}

Each of the preview conditions was compared individually with the full-set baseline for a measure of whether any preview benefit occurred (measured in terms of the interactions of slope functions between the conditions and the display size).

Full-set baseline versus $\mathbf{I}+\mathbf{I}: \mathbf{1 , 0 0 0}$. The main effects of both condition $[F(1,22)=18.30, p<.001]$ and display size $[F(1,22)=225.35, p<.001]$ were significant. The condition $\times$ display size interaction was not reliable $[F(1,22)=0.31, p=.586]$. RTs were shorter overall in the preview condition, but search efficiency was not improved, relative to the full-set baseline (see Figure 1).

Full-set baseline versus $\mathbf{I}+\mathbf{I}: \mathbf{3 , 0 0 0}$. The main effects of both condition $[F(1,22)=18.04, p<.001]$ and display size $[F(1,22)=163.41, p<.001]$ were significant. The condition $X$ display size interaction was also reliable $[F(1,22)=14.12, p<.01]$. Search efficiency was considerably improved for the preview condition, relative to performance in the full-set baseline condition (see Figure 1).

\section{Preview Comparisons}

We also compared the 1,000- and the 3,000-msec preview conditions together for a measure of search improvement as a function of the preview duration.

I+I: $\mathbf{1 , 0 0 0}$ versus $\mathbf{I}+\mathbf{I}: \mathbf{3 , 0 0 0}$. The main effect of condition was not reliable $[F(1,22)=0.15, p=.707]$. The main effect of display size was significant $[F(1,22)=$ $142.34, p<.001$ ], as was the reliable condition $\times$ display size interaction $[F(1,22)=22.49, p<.001]$. Search efficiency improved when the participants were given a longer preview duration (in the I+I: 3,000 condition), relative to the shorter preview duration condition (see Figure 1). 
Table 1

Intercept and Slope Functions for All Search Conditions in Experiment 1

\begin{tabular}{lcc}
\hline Condition & Intercept & Slope (msec/Item) \\
\hline Full-set & 648 & 21 \\
I+I: 1,000 & 607 & 20 \\
I+I: 3,000 & 698 & 12 \\
\hline
\end{tabular}

Note-We take slope as the measure of search efficiency.

\section{Errors}

Overall, the error rate was low at $2.92 \%$. Errors were analyzed, like RTs, in an overall $4 \times 2$ (condition $\times$ display size) within-subjects ANOVA. Only the main effect of display size reached significance $[F(1,22)=7.884, p<$ .05 ; all other $F \mathrm{~s}<2]$. There was no evidence of a speedaccuracy trade-off.

\section{Discussion}

The results from Experiment 1 are clear. First, as measured by the slope of the search function, performance for the standard duration preview condition (I+I: 1,000) showed no improvement in search efficiency, relative to the full-set baseline. This finding supports other studies (Donk $\&$ Theeuwes, 2001) and confirms that we achieved accurate isoluminant properties with our displays. Search in this preview condition was clearly very difficult. In contrast, search efficiency was greatly improved when the preview duration was larger (I+I: 3,000), and the effects of display size were then less than those in both the full-set baseline and the 1,000 -msec preview conditions. Providing the participants with an increased preview period produced a substantial and robust preview benefit.

This new finding goes against the argument that abrupt onsets alone are necessary and sufficient to generate a preview benefit (Donk \& Theeuwes, 2001). Neither the preview nor the search display arrived with an abrupt onset, so any advantage here cannot be due to the presence of this signal. One curiosity within the data was the increased intercept for the I+I: 3,000 condition, relative to the standard $1,000-\mathrm{msec}$ preview condition. It is most likely that this represents a difference in the overall level of arousal associated with anticipating a new event, which takes longer to occur. Furthermore, it is also the case that the appearance of the search display is more difficult to predict after this period, as compared with when the preview-search-display interval is shorter. Both of these factors would cause a delay in the initiation of search into those items (see also Watson \& Humphreys, 1997, for a similar discussion).

What these results suggest is that improved search efficiency can be obtained with preview and search items presented at isoluminance, although the preview benefit may not be optimal and may require more time to establish than when the stimuli are nonisoluminant. These findings are important for understanding how the preview may come about. Watson et al. (2003) suggested that preview items must be represented within a system that codes luminance discontinuities, in order for them to be suppressed and filtered out from search. However, the present findings suggest that inhibitory filtering may take place, to some degree, even in the absence of such luminance-defined signals. Nevertheless, the present findings are consistent with the preview advantage reflecting the encoding and subsequent inhibition of the locations of the old items (i.e., visual marking). Simply put, when the stimuli are isoluminant with their background, location coding is less efficient. As a consequence, visual marking takes a longer time to establish.

Although these results are consistent with a visualmarking account, other suggestions can be considered. One possibility is that performance could be improved at the longer duration because observers now have the time to serially search all of the old items, with inhibition of return (IOR) being applied to all the old items (see Klein, 1988, 2000). However, this explanation seems unlikely. For instance, other studies in which abrupt onset stimuli

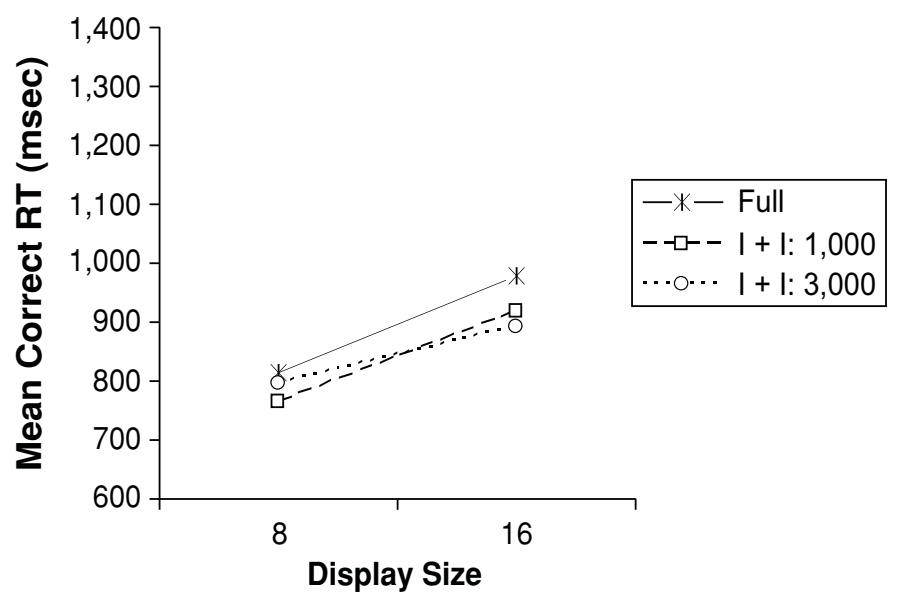

Figure 1. Mean correct response times (RTs) for the full-set baseline, I+I: 1,000 preview, and I+I: 3,000 preview conditions in Experiment 1 . 
have been used have also shown a functional distinction between serial IOR and visual marking. Olivers, Humphreys, Heinke, and Cooper (2002) presented targets in either the old or the new displays. The participants initiated the presentation of the new displays by pressing a key after they were satisfied that the target was not part of the first display. This should have allowed serial IOR to be applied to each of the old items before the search display appeared. Despite this, search was little better than in the full-set baseline condition and much worse than when the participants could set themselves to attend to the second display (the standard preview condition). Apparently, serial IOR was not sufficient to produce the standard preview benefit. Therefore, the very act of serially searching the preview items appears to have a detrimental impact on the ability to restrict search to items in the second display.

Other evidence against an IOR interpretation can be taken from the capacity limitations apparent for IOR. For instance, Snyder and Kingstone (2000) have shown that IOR can exist for a maximum of around 5 items in total. In the present experiments, the larger display size was 16 items; for preview conditions, this meant that there were 8 items in the preview display and 8 items in the search display. Theeuwes, Kramer, and Atchley (1998) have reported a preview benefit with as many as 15 old items. This is beyond the known capacity of IOR. In addition, the smaller display size used here (4 old, 4 new items) is within the capacity of IOR, yet there was no benefit at this display size as the preview duration lengthened. Serial IOR does not seem to be critical for the present results.

Two other alternatives can be suggested, however. One is that the ability to temporally segment the old and the new items is disrupted when the items are isoluminant, so that efficient segmentation is not achieved even with a 1,000msec stimulus onset asynchrony (SOA) between the displays. When the SOA is increased to $3,000 \mathrm{msec}$, segmentation is possible, and a preview benefit results (see Jiang et al., 2002).

A further possibility is that the improvement at the longer preview duration may be due not to the effects of top-down inhibition, but to low-level sensory fatigue. For instance, it may be that at a low level, neurons in the visual system saturate in firing as a result of the more prolonged preview duration. The new items are then advantaged, because neurons at those locations are not fatigued. In Experiment 2, we sought to test these alternative accounts directly.

Experiment 2 employed a centrally presented, attentionally demanding task during the 3,000-msec preview duration. We reasoned that if the improved performance from the prolonged preview period was due to attentionaldependent filtering of the old items, a demanding task could disrupt preview search by reducing the resources available to encode and inhibit the old items (Humphreys et al., 2002; Watson \& Humphreys, 1997). Conversely, if the improvement in preview search at the longer duration is based in sensory factors, the use of an additional attentional task should not impact on performance; indeed, it may even make the old items easier to ignore, since sensory fatigue should be increased by the participants' fixating throughout the preview period in order to perform the secondary task (see Theeuwes \& Lucassen, 1993). In either case, we would expect a robust preview advantage to occur.

In the secondary task, we presented at fixation a stream of numbers sequentially, one after the other (one every $250 \mathrm{msec}$ ). These numbers ranged from 0 to 9 , and they were also presented at isoluminance. For the preview condition, this number stream started when the preview items were presented and continued up until the presentation of the search display. The participants were told to monitor this stream of numbers for the frequency of occurrence of a target number (the number 2), which could occur once, twice, or three times randomly on any trial. This secondary task was also coupled to a new full-set baseline. In this case, a stream of numbers occurred first (for 3,000 msec) before the whole search display was presented.

Finally, Experiment 2 also employed a half-set baseline condition, matched to just the new items in the preview condition. The reason for this was that although Experiment 1 showed a clear search advantage when the preview duration increased relative to the full-set baseline, it was not possible to determine whether this represented a full or a partial preview benefit. If search not only can be improved, but also can be optimized under isoluminant conditions, this would provide further evidence against the idea that onsets are unique for generating a preview advantage.

\section{EXPERIMENT 2 Inhibition or Sensory Fatigue?}

\section{Method}

\section{Participants}

Sixteen participants ( 10 of them female, 1 left-handed) took part for course credit or a small payment. The age of the participants ranged from 19 to 32 years, with a mean age of 22 years. All were undergraduate or postgraduate students at the University of Birmingham. All had self-reported normal (including normal color vision) or corrected-to-normal vision.

\section{Stimuli and Apparatus}

All the stimuli were similar to those in Experiment 1, with the exception that here, two new dual-task (DT) conditions were created. These will be outlined below.

\section{Design and Procedure}

A $5 \times 2$ (condition $\times$ display size) within-subjects design was used. In order to replicate Experiment 1, the full-set baseline and the preview (I+I: 3,000) conditions were included. In addition, we created the following new conditions: (1) a half-set baseline consisting of just the second set of items from the preview condition (4 or 8 items), (2) a full-set baseline coupled to a centrally presented task (Full: DT), and (3) a preview condition with a dual task at fixation during the preview period (I+I: 3,000 DT). For the full-set dualtask condition, each trial began with the presentation of a fixation cross for $1,000 \mathrm{msec}$. This cross was then removed, and a series of numbers were presented (between 0 and 9) at a rate of one every $250 \mathrm{msec}$, for a total duration of 3,000 msec. This number stream appeared at isoluminance. The participants were told to monitor this central stream and to count how many times the number 2 occurred. The target number could occur once, twice, or three times pseudorandomly, with the following restrictions. First, if only one 
target number was to be presented, it could occur randomly at any point during the $3,000 \mathrm{msec}$ period. Second, if more than one target number occurred, those numbers could not occur directly after one another (there was always a randomly chosen distractor number in between target numbers in this case). Third, in the case in which three target numbers occurred, each target number was presented at a random point within its own 1,000-msec period (e.g., a target number in the first $1,000 \mathrm{msec}$, one in the second $1,000 \mathrm{msec}$, and one in the third $1,000 \mathrm{msec}$ ). After the sequence had been presented, the letter search stimuli were displayed, and the participants had to discriminate whether the target was a $T$ or an $L$. On completion of this search task, the computer asked, "How many number $2 \mathrm{~s}$ were presented, 1, 2, or 3?" The participants responded by typing in the number, and the accuracy of the response was recorded. In the fullset condition, 8 and 16 new items were presented; in the half-set baseline, four and eight new stimuli appeared. For the preview condition, the centrally presented letter stream began on the presentation of the preview items, and it again lasted for 3,000 msec. This task ended when the search display was presented. For the Full: DT condition, the number stream task was presented first (for 3,000 msec); then the whole search display appeared. The observers then searched for the target letter from the display before answering the question concerning how many number 2 s occurred during the sequence. The remaining procedure matched that in Experiment 1.

\section{Results}

The RT data were prepared for analysis in the same way as that outlined in Experiment 1. An overall $5 \times 2$ (condition $\times$ display size) within-subjects ANOVA was run on the correct RT data. This revealed significant main effects of both condition and display size $[F(4,60)=1.77, p<.001$, and $F(1,15)=122.72, p<.001$, respectively]. The condition $\times$ display size interaction was also reliable $[F(4,60)=$ $9.52, p<.001]$. This interaction was further decomposed in the manner outlined below. Table 2 shows descriptive intercept and slope values for all the conditions in Experiment 2 .

\section{Half-Set Versus Preview Comparisons}

Half-set versus I+I: 3,000. The main effects of both condition $[F(1,15)=20.56, p<.001]$ and display size $[F(1,15)=31.06, p<.001]$ were significant. The condition $\times$ display size interaction was not reliable $[F(1,15)=$ $2.43, p=.140]$. Although overall RTs from the preview condition were longer, relative to the half-set baseline, search efficiency (the slopes of the search functions) was equivalent in both conditions (see Figure 2).

Half-set versus I+I: 3,000 DT. The main effects of both condition and display size were significant $[F(1,15)=$ $62.21, p<.001$, and $F(1,15)=61.15, p<.001$, respectively]. The condition $X$ display size interaction was also

Table 2

Intercept and Slope Functions for All Search Conditions in Experiment 2

\begin{tabular}{lcc}
\hline \multicolumn{1}{c}{ Condition } & Intercept & Slope (msec/Item) \\
\hline Half-set & 728 & 6 \\
Full-set & 720 & 23 \\
Full: DT & 890 & 27 \\
I+I: 3,000 & 814 & 11 \\
I+I: 3,000 DT & 955 & 19 \\
\hline
\end{tabular}

significant $[F(1,15)=17.20, p<.01]$. Search in the dualtask preview condition was slower and less efficient, relative to the half-set baseline (see Figure 2).

\section{Full-Set Versus Preview Comparisons}

Full-set versus I+I: 3,000. The main effect of condition was not significant $[F(1,15)=1.75, p=.206]$. The main effect of display size $[F(1,15)=93.24, p<.001]$ and the condition $\times$ display size interaction $[F(1,15)=21.38$, $p<.001]$ were reliable. Search performance was more efficient in the preview, relative to the full-set baseline.

Full: DT versus I+I: 3,000 DT. Only the main effect of display size was significant $[F(1,15)=70.26, p<$ $.001]$. Neither the main effect of condition $[F(1,15)=$ $0.90, p=.357]$ nor the condition $\times$ display size interaction $[F(1,15)=2.52, p=.134]$ was reliable.

\section{Effect of the Dual Task in the Preview Condition}

I+I: 3,000 versus I+ I: 3,000 DT. The main effects of both condition $[F(1,15)=13.45, p<.01]$ and display size $[F(1,15)=58.02, p<.001]$ were significant. The condition $\times$ display size interaction was also reliable $[F(1,15)=$ 7.38, $p<.05]$. Performance was faster and more efficient when the preview appeared alone than when it was presented in the context of an ongoing concurrent secondary task (see Figure 3).

\section{Full-Set Comparison}

Full-set versus Full: DT. The main effects of both condition and display size were significant $[F(1,15)=7.58$, $p<.05$, and $F(1,15)=81.86, p<.001$, respectively]. The condition $\times$ display size interaction was not significant $[F(1,15)=0.59, p=.455]$. Search efficiency was matched across the two full-set baseline conditions.

\section{Errors}

For the search task, overall, the error rate was low at $2.79 \%$. For the number detection task, the errors were slightly higher at $7.94 \%$. This indicates that the centrally presented task was indeed attentionally demanding. Search errors were analyzed, like RTs, in an overall $5 \times 2$ (condition $\times$ display size) within-subjects ANOVA. This revealed significant main effects of condition $[F(4,60)=3.68$, $p<.05]$ and display size $[F(1,15)=5.32, p<.05]$. The condition $\times$ display size interaction was not significant $[F(4,60)=0.71, p=.590]$. The number task errors for the two dual-task conditions were analyzed in a $2 \times 2$ (condition $\times$ display size) within-subjects ANOVA. This revealed no significant effects (all $F_{\mathrm{s}}<4$, and all $p \mathrm{~s}>.09$ ). There was no sign of a speed-accuracy trade-off.

\section{Discussion}

The findings from Experiment 2 were as follows. First, the results in the prolonged preview and full-set baselines replicated those reported in Experiment 1. We again found a significant improvement in search efficiency when there was a prolonged preview (I+I: 3,000), relative to a full-set baseline. However, here, we also ran a half-set baseline to 

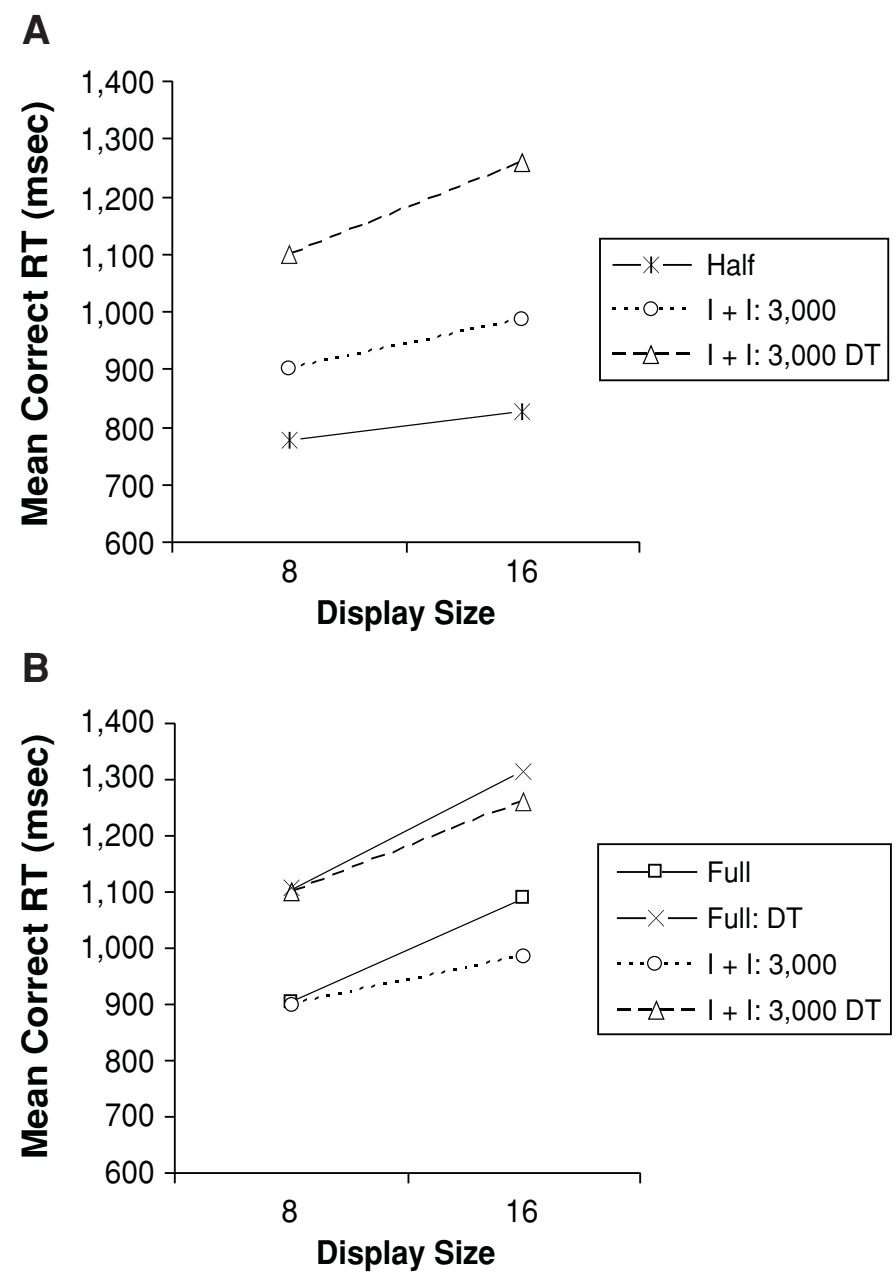

Figure 2. Mean correct response times (RTs) for the (A) half-set baseline, I+I: 3,000 preview, and I+I: 3,000 DT preview conditions and (B) the $I+I$ : 3,000 preview and $I+I$ : 3,000 DT preview conditions, as compared with the full-set baseline and full-set dual-task baseline conditions, in Experiment 2.

ascertain whether search in the preview was as efficient as that when only the new items appeared. Search efficiency for the preview and the half-set conditions did not differ. This indicates that search in the preview operated only through the second items.

In contrast to the data when previews appeared alone, we found that an attentionally demanding task occurring during the preview period abolished the preview advantage. Here, search performance was reduced to the same level of efficiency as when the old and the new items were presented simultaneously (in the full-set baseline). Clearly, these results show that preview search suffered under dualtask conditions even with a 3,000 msec preview period and that the old items then could not be ignored. This result goes against the sensory fatigue account of the preview benefit and against the idea that isoluminant items become temporally segmented after $3,000 \mathrm{msec}$. In contrast, the data are consistent with the idea that limited-capacity attentional resources are crucial to the preview benefit. We suggest that under dual-task conditions, resources are taken away from encoding and the inhibiting of the preview and, as a consequence, the preview items remain available to compete with the new items in search (Humphreys et al., 2002; Watson \& Humphreys, 1997).

It is also interesting to note that the secondary task abolished the preview benefit. In previous studies in which a similar central load task was employed, but with nonisoluminant stimuli (e.g., Humphreys et al., 2002; Watson \& Humphreys, 1997), the preview benefit has been reduced but not abolished (i.e., search efficiency fell between the half-set and the full-set baselines). The present finding supports our proposal that any marking of isoluminant old stimuli is more difficult/resource-demanding than is marking of items defined by a luminance difference. As a consequence, ignoring old isoluminant stimuli takes longer and is more susceptible to interference from competing tasks. 
One final aspect of the data worth noting is the difference between the dual-task conditions and the standard conditions, in terms of overall RTs or intercept costs. We have used slopes as a measure of search efficiency in this study. Although it has been argued that intercepts can be revealing in some circumstances (Jiang et al., 2002), it can be difficult to draw firm conclusions about what intercept differences represent. This is because intercept differences could stem from several factors, including arousal differences, switching from suppressing distractors to searching new displays, or even inhibiting a response to the first display (see Watson \& Humphreys, 1997, for a fuller discussion). In the context of the present experiments, such further costs may be attributed to an overall delayed allocation of search resources under dual-task conditions, perhaps_reflecting delayed disengagement from the centrally presented dual task (relative to the non-dual-task conditions).

To summarize, taken together, the findings contradict the idea that old items cannot be ignored with isoluminant search displays (Donk \& Theeuwes, 2001; Watson et al., 2003). Instead, old items can be ignored in isoluminant displays if there is sufficient time between the old and the new displays and if the participants have sufficient resources available during the preview period. These findings have important implications for inhibitory architectures underlying the preview search advantage.

\section{GENERAL DISCUSSION}

This article has reported two experiments in which preview search was investigated when the stimuli were isoluminant with their background. Of particular interest was whether preview benefits were impossible under isoluminant conditions or whether they were possible, providing that there was sufficient time given for them to occur. Experiment 1 demonstrated that a benefit could occur, provided that the preview display was presented for a sufficiently long duration. Experiment 2 extended this by showing that under these conditions, a full preview benefit could occur; it also provided evidence that low-level sensory factors were not crucial to this effect. Notably, the preview benefit was abolished when the participants undertook a secondary task during the preview period.

\section{Accounts of Preview Search}

The finding that a preview benefit occurs with isoluminant stimuli provides strong evidence against an account of performance simply in terms of attentional capture by new onsets (Donk \& Theeuwes, 2001). This supports the results of Braithwaite et al. (2005) and Humphreys et al. (2004), who also found a preview benefit when the new items were not defined by onsets. New onsets are not necessary for a preview benefit. However, we also showed that when the stimuli were isoluminant with their background, the preview had to be presented for a prolonged period before any benefit emerged. Experiment 2 provided an explicit test of whether the old items could be ignored with prolonged displays, due to neural fatigue.
This sensory account was rejected, because the previews did have an impact on performance even with a prolonged exposure, when the participants were engaged in a secondary task during the preview period. This also goes against an account in terms of improved temporal segmentation. Neither sensory exposure nor delayed segmentation is sufficient to account for the data.

Finally, the present data counter an account of preview search in terms of serial IOR to the old stimuli. In both Experiments 1 and 2, the preview benefit was greater at larger display sizes and was minimal at smaller display sizes, yet only the smaller display sizes fell within the likely capacity of serial IOR (Snyder \& Kingstone, 2000). Instead of the accounts above, we propose that the preview benefits here were linked to better encoding and inhibition of the previews under the prolonged presentation conditions. We suggest that it is relatively difficult to encode the locations of old items that are isoluminant with their background (Livingstone \& Hubel, 1987). With prolonged exposures, the old items can be encoded and inhibited to some degree, allowing attention to be prioritized to the new stimuli. Furthermore, taking attention away from the old items meant that there were fewer resources available to encode and inhibit the previews. Any benefit for search efficiency was then eliminated.

\section{Alternative Low-Level Accounts}

In Experiment 2, we tested for, and rejected, the possibility that low-level sensory fatigue could be responsible for the preview benefit at increased durations. However, it could be argued that another form of low-level account is crucial. For instance, it may be that a form of color adaptation could operate (particularly in the I+I: 3,000 condition), which may facilitate search. ${ }^{1}$ Theeuwes and Lucassen (1993) reported an adaptation effect that could influence pop-out search in some circumstances. They presented observers with 15 red circles (for up to 3,000 msec, in some cases). The display then disappeared and was replaced by 15 gray circles, each containing a single orientated line segment. The task was to indicate whether a vertical or a horizontal line segment target was present in any of the circles (an inefficient search task). In one condition, all of the gray circles fell at locations that had not previously been occupied by the red circles, and target search was inefficient. In another condition, one of the gray circles (containing the target) fell at the location of a previously displayed red circle, and search was then very efficient. It was argued that the new stimulus falling at a previously occupied location was perceived as having a color different from those appearing at new locations, due to local color adaptation from the earlier stimulus (and hence, was detected efficiently).

Applied to the preview paradigm, the argument predicts that at longer preview durations, the old and the new items will actually be perceived as having different colors, due to the fact that the visual system will have adapted, to some degree, to the activations of the old preview items. Color-based segmentation of the displays will then enable search to be guided to the new items (Theeuwes \& Lucassen, 1993). 
However, there are a number of reasons why this particular form of color adaptation seems unlikely as an explanation for the present results. First, Theeuwes and Lucassen's (1993) study showed that color adaptation effects took place after 100-250 msec. On the basis of these demonstrations and temporal estimations, it is thus not clear why we failed to get a preview benefit with a 1,000 -msec preview duration (in Experiment 1) and got one only at a 3,000-msec duration. Presumably, here, at time frames well in excess of 100-250 msec, any effects of color adaptation should be manifest in both 1,000- and 3,000-msec preview conditions. Therefore, it cannot be a viable explanation for the performance differences observed between these conditions. Preview durations of $1,000 \mathrm{msec}$ should be more than sufficient to induce an adaptation effect with these stimuli, if indeed it were crucial. Clearly, this was not the case. Furthermore, color adaptation should have operated in Experiment 2 (and indeed, it should have increased in the dual task, since fixation was then more likely at the center of the initial display throughout the preview period). The data go against this, since the preview benefit was eliminated by the secondary task in this experiment.

\section{Implications for Inhibitory Architectures}

In order to account for the earlier findings of Donk and Theeuwes (2001), where preview search was poor with isoluminant stimuli, Watson et al. (2003) suggested that visual marking was applied only within a system sensitive to luminance discontinuities (a dynamic detection system; Watson et al., 2003). However, none of these prior accounts would predict the present finding of a benefit in search efficiency in the preview condition when both preview and search items were isoluminant with their background. This may suggest that there is inhibition in a system in which colors, rather than luminance discontinuities, are coded. Within this system, stimuli are suppressed only across a prolonged time course. Alternatively, it is quite possible that the inhibition of locations defined by isoluminant stimuli still takes place via inhibition applied within a luminance-sensitive system but that obtaining the locations of the stimuli in the first place takes longer before the inhibition can be applied. On this view, inhibition is applied within the same spatial representation system, irrespective of whether the stimuli are isoluminant with their background or not. The observed lack of preview benefits with isoluminant stimuli in previous studies, then, simply resulted from an inability to efficiently code their locations in the time period given, and not from the fact that such coding could not take place. This is not to state that luminance discontinuities are not important for preview search. For instance, the time course of performance is much shorter when both the old and the new stimuli are defined by onsets (Watson \& Humphreys, 1997), and onset capture by new stimuli may also contribute to search efficiency. When onset stimuli are used, preview durations of around $400 \mathrm{msec}$ are sufficient to generate a substantial benefit to search (see Watson \& Humphreys, 1997). This may be because the locations of onset stimuli are coded and deprioritized more effectively when they are registered in a system sensitive to such dynamic change.
The present data, though, show that onsets themselves are not necessary.

These findings are important for any functional architecture seeking to model the collective findings from preview search studies. For instance, a preview benefit can occur if just the new items arrive with an abrupt onset (Donk \& Theeuwes, 2001) or the preview items have arrived with an abrupt onset (Watson et al., 2003). Previous suggestions for inhibitory architectures have stressed the links between inhibitory templates and a dynamic detection system (Watson \& Humphreys, 1997; Watson et al., 2003). However, although such conditions can be sufficient, the present findings suggest that they are not always necessary. Inhibition can be applied to isoluminant items if given sufficient time to do so. Whether this filtering represents a completely different processing system or secondary processes within a system whose primary networks are compromised is open to debate. In conclusion, the present study provides evidence that the preview benefit cannot be accounted for on the basis of automatic attentional capture by abrupt luminance onsets alone (cf. Donk \& Theeuwes, 2001).

\section{REFERENCES}

BraithwaIte, J. J. (2002). Visual search in space and time: Where attention and inattention collide? Unpublished PhD thesis, University of Birmingham.

Braithwaite, J. J., \& Humphreys, G. W. (2003). Inhibition and anticipation in visual search: Evidence from effects of color foreknowledge on preview search. Perception \& Psychophysics, 65, 213-237.

Braithwaite, J. J., Humphreys, G. W., \& Hodsoll, J. (2003). Color grouping in space and time: Evidence from negative color-based carryover effects in preview search. Journal of Experimental Psychology: Human Perception \& Performance, 29, 758-778.

Braithwaite, J. J., Humphreys, G. W., \& Hodsoll, J. (2004). Effects of colour on preview search: Anticipatory and inhibitory biases for colour. Spatial Vision, 17, 389-415.

Braithwaite, J. J., Humphreys, G. W., \& Hulleman, J. (2005). Colorbased grouping and inhibition in visual search: Evidence from a probe detection analysis of preview search. Perception \& Psychophysics, 67, 81-101.

Braithwaite, J. J., Humphreys, G. W., Watson, D. G., \& Hulleman, J. (2005). Revisiting preview search at isoluminance: New onsets are not necessary for the preview advantage. Perception \& Psychophysics, 67, 1214-1228.

Donk, M., \& Theeuwes, J. (2001). Visual marking beside the mark: Prioritizing selection by abrupt onsets. Perception \& Psychophysics, 63, 891-900.

Gibson, B. S., \& JiAng, Y. (2001). Visual marking and the perception of salience in visual search. Perception \& Psychophysics, 63, 59-73.

Humphreys, G. W., Stalmann, B. J., \& Olivers, C. [N. L.] (2004). An analysis of the time course of attention in preview search. Perception \& Psychophysics, 66, 713-730.

Humphreys, G. W., Watson, D. G., \& Joliceur, P. (2002). Fractionating the preview benefit in search: Dual-task decomposition of visual marking by timing and modality. Journal of Experimental Psychology: Human Perception \& Performance, 28, 640-660.

JiAnG, Y., Chun, M. M., \& MARKs, L. E. (2002). Visual marking: Selective attention to asynchronous temporal groups. Journal of Experimental Psychology: Human Perception \& Performance, 28, 717-730.

KLEIN, R. M. (1998). Inhibitory tagging system facilitates visual search. Nature, 334, 430-431.

KLEIN, R. M. (2000). Inhibition of return. Trends in Cognitive Sciences, 4, 138-147.

Livingstone, M. S., \& Hubel, D. H. (1987). Psychophysical evidence for separate channels for the perception of form, color, movement, and depth. Journal of Neuroscience, 7, 3416-3468. 
Olivers, C. N. L., \& Humphreys, G. W. (2002). When visual marking meets the attentional blink: More evidence for top-down, limited capacity inhibition. Journal of Experimental Psychology: Human Perception \& Performance, 28, 22-42.

Olivers, C. N. L., \& Humphreys, G. W. (2003). Visual marking inhibits singleton capture. Cognitive Psychology, 47, 1-42.

Olivers, C. N. L., Humphreys, G. W., Heinke, D., \& Cooper, A. C. G. (2002). Prioritization in visual search: Visual marking is not dependent on a mnemonic search. Perception \& Psychophysics, 64, 540-560.

Snyder, J. J., \& Kingstone, A. (2000). Inhibition of return and visual search: How many separate loci are inhibited? Perception \& Psychophysics, 62, 452-458.

Theeuwes, J., Kramer, A. F., \& Atchley, P. (1998). Visual marking of old objects. Psychonomic Bulletin \& Review, 5, 130-134.

Theeuwes, J., \& Lucassen, M. P. (1993). An adaptation-induced popout in visual search. Vision Research, 33, 2353-2357.

Watson, D. G., \& Humphreys, G. W. (1997). Visual marking: Prioritizing selection for new objects by top-down attentional inhibition of old objects. Psychological Review, 104, 90-122.

Watson, D. G., \& Humphreys, G. W. (1998). Visual marking of moving objects: A role for top-down feature-based inhibition in selection. Journal of Experimental Psychology: Human Perception \& Performance, 24, 946-962.
Watson, D. G., \& Humphreys, G. W. (2000). Visual marking: Evidence for inhibition using a probe-dot detection paradigm. Perception \& Psychophysics, 62, 471-481.

Watson, D. G., \& Humphreys, G. W. (2002). Visual marking and visual change. Journal of Experimental Psychology: Human Perception \& Performance, 28, 379-395.

Watson, D. G., Humphreys, G. W., \& Olivers, C. N. L. (2003). Visual marking: Using time in visual selection. Trends in Cognitive Sciences, 7, 180-186.

Yantis, S. (1993). Stimulus-driven attentional capture. Current Directions in Psychological Science, 2, 156-161.

Yantis, S. (1996). Attentional capture in vision. In A. F. Kramer, M. G. H. Coles, \& G. D. Logan (Eds.), Converging operations in the study of visual selective attention (pp. 45-77). Washington, DC: American Psychological Association.

\section{NOTE}

1. We thank Jan Theeuwes for this suggestion.

(Manuscript received April 22, 2004; revision accepted for publication April 28, 2005.) 